\title{
La reconstrucción de un palimpsesto románico mediante técnicas no destructivas
}

\section{The reconstruction of a romanesque palimpsest by means of non destructive techniques}

J. Lluis i Ginovart $^{(*)}$, A. Costa-Jover ${ }^{(*)}$, S. Coll-Plá $\left.{ }^{*}\right)$

\section{RESUMEN}

La catedral gótica de Tortosa (1346), se superpone sobre una construcción románica (1178) a modo de palimpsesto, de la cual no existe ninguna evidencia física. La prospección geofísica (2102-13), ha aportado algunos datos relevantes de la anterior seo, que han precisado la ubicación de alguna de sus partes principales: ábside, pilares de la nave y fachada. Con estos datos se puede entender el encaje del proceso, constructivo/deconstructivo de ambos edificios. El estudio concluye que los elementos estructurales más importantes de ambas edificaciones encajan a manera de engranaje, y se deducen las posibles dimensiones de la Seo románica en base a las evidencias encontradas en el subsuelo.

Palabras clave: Catedral; georadar; gótico; románico; Tortosa

\section{ABSTRACT}

The Gothic Cathedral of Tortosa (1346), is superposed over a Romanesque building (1178) as a palimpsest, which there is no physical evidence. The geophysical survey (2102-13), has provided some relevant data from the previous seo, which have enabled the location of some of its main features: apse, pillars of the nave and façade. With these data it is possible to understand the fitting of the process, constructive/ deconstructive of both buildings. The study concludes that the main structural elements of both buildings fit as a gear, and the possible dimensions of the Romanesque Seo are deducted through the evidences found in the subsoil.

Keywords: Cathedral; georadar; gothic; romanesque; Tortosa

(*) Universitat Rovira i Virgili. Reus (España).

Persona de contacto/Corresponding author: josep.lluisg@urv.cat (J. Lluis i Ginovart)

Cómo citar este artículo/Citation: Lluis i Ginovart, J., Costa-Jover, A., Coll-Plá, S. (2014). La reconstrucción de un palimpsesto románico mediante técnicas no destructivas. Informes de la Construcción, 66(536): eo45, doi: http://dx.doi.org/10.3989/ic.13.184.

Licencia/License: Salvo indicación contraria, todos los contenidos de la edición electrónica de Informes de la Construcción se distribuyen bajo una licencia de uso y distribución Creative Commons Reconocimiento no Comercial 3.o. España (cc-by-nc). 


\section{INTRODUCCIÓN}

En 1346 el Capítulo y el obispo de la catedral de Tortosa, encargan al magíster operis, Bernat Dalguaire (+1347), la construcción de una nueva catedral que debía sustituir la seo románica, cuya acta de consagración y dotación fue el 28 de noviembre de 1178 (1). La primera piedra del nuevo templo, fue colocada el 21 de mayo de 1347, iniciándose un proceso de construcción y deconstrucción, con una superposición de la catedral gótica sobre una románica a modo de palimpsesto (Figura 1).

La construcción gótica responde la nueva liturgia del Prochiron, vulgo rationale divinorum officiorum, (1291) de Guillermo de Durando (1230-1296)․․ El Prochiron definirá la correspondencia entre la ecclesia materialis y la ecclesia spiritualis) (2). La liturgia busca el uso correcto y la caracterización de la imaginería cristiana en el ambiente litúrgico (3). La nueva liturgia de Durando había sustituido a la visión alegórica de la Gemma animae (c.1120), de Honorio de Autun (1080-c.1153), sobre la que se había construido la catedral románica (4). La proliferación de las capillas radiales y laterales, consecuencia del Prochiron provocará, o bien la remodelación de las cabeceras románicas, o bien la sustitución progresiva de las seos románicas. La nueva tipología fue ensayada en las catedrales del Sur de Francia, Clermont-Ferrand (1248), Narbona (1272) y Limoges (1273) y exportadas a Catalunya, con la sustitución progresiva de las sedes románicas por las góticas, caso de Gerona en 1312 (5), Barcelona 1317 (6) y la catedral de Tortosa a partir de 1345.

El canónigo José Matamoros Sancho (1866-1937), siguiendo la tradición historiográfica, ubica el templo románico a los pies de la actual basílica (7). La divulgación de los dibujos de Antoon van den Wyngaerde (1525-1571) en las vista de la ciudad de Tortosa (1563) \{Osterreichische Nationalbibliothek, Viena, Picture Archive, Cod.min 41, fol. 7r, fol. 8 r, fol 8 v.\} (8) (9) (10), permite identificar la cabecera de la nueva catedral gótica, sobre el mismo eje de la construcción románica (Figura 2).

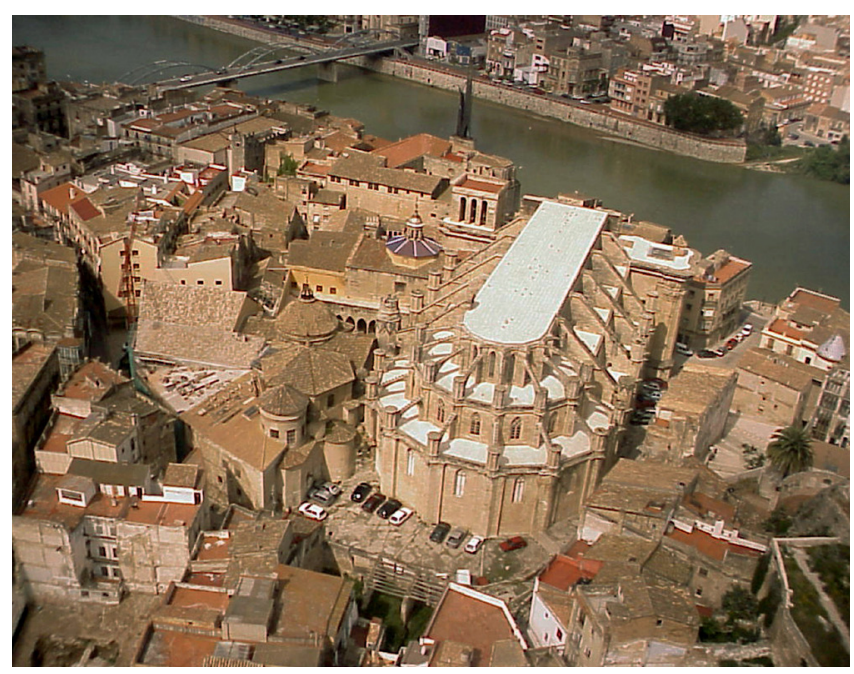

Figura 1. Catedral Santa Maria de Tortosa.

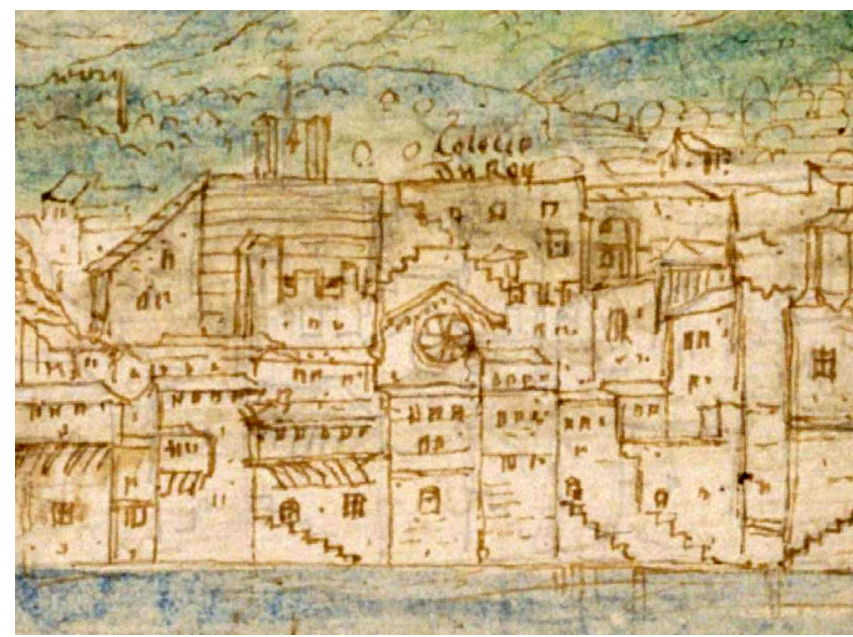

Figura 2. Detalle fachada Oeste catedral de Tortosa (1563).

Antoon van den Wyngaerde (1525-1571). Osterreichische

Nationalbibliothek, Viena. Picture Archive, Cod.min 41 ffol. 8 r\}.

Será Mons. Aurelio Querol Lor (1917-1994), en el Programa Oficial de Setmana Santa (1992) (11) quien cuestione abiertamente la tesis de la ubicación de la catedral románica que hasta el momento se ha había propiciado. Almuni divulgará la coincidencia de la catedral vieja con el cuerpo del templo actual en la Catalunya Románica (1985-1998) (12). Esta circunstancia es tenida en cuenta en la elaboración del Plan Director de la catedral de Tortosa (13), publicado en Sancta Maria Dertosae. Catedral de Tortosa (14). Con todo ello, Almuni (2004) y (2007) publicará el primer estudio específico sobre la catedral románica de Tortosa, con una hipótesis de ubicación imprecisa topográficamente (15) (16).

\section{OBJETIVO Y METODOLOGÍA}

De la construcción románica no existen evidencias físicas. La ubicación de la catedral antigua planteaba dos hipótesis plausibles. El canónigo Matamoros (1932), la disponía perpendicular al eje actual, con orientación Norte-Sur, y próxima a la fachada principal. Victoria Almuni (2004), la sitúa en una disposición similar a la catedral actual, orientada de Este-Oeste (Figura 3). El estudió tiene como objetivo plantear mediante un análisis no destructivo, con métodos geofísicos, la ubicación de la antigua catedral románica.

Las técnicas de prospección arqueológicas de Richard J.C. Atkinson (1920-1994), mostrando imágenes legibles y fiables de estructuras arqueológicas enterradas (17), son el precedente de la aplicación de prospecciones geofísicas. Los avances instrumentales de las propuestas técnicas en la década de los 70 y finales del siglo XX (18) (19), propiciaron su aplicación en el estudio de estructuras arquitectónicas en el subsuelo (20).

En España se han utilizado en el estudio de algunas catedrales, como Gerona (2000) (21) (22), Valencia (2000) (23) y Burgos (2002) (24). La técnica todavía es operativa completando metodologías sobre prospecciones geofísicas actuales

\footnotetext{
La nueva liturgia era conocida por los canónigos de Tortosa. Códice ACTo nº58, (f. XIII), y los incunables de la edición de Roma (1477) (ACTo $\mathrm{n}^{0}{ }_{258}$ ) y la de Venecia (1482) (ACTo $\mathrm{n}^{0} 290$ ).
} 


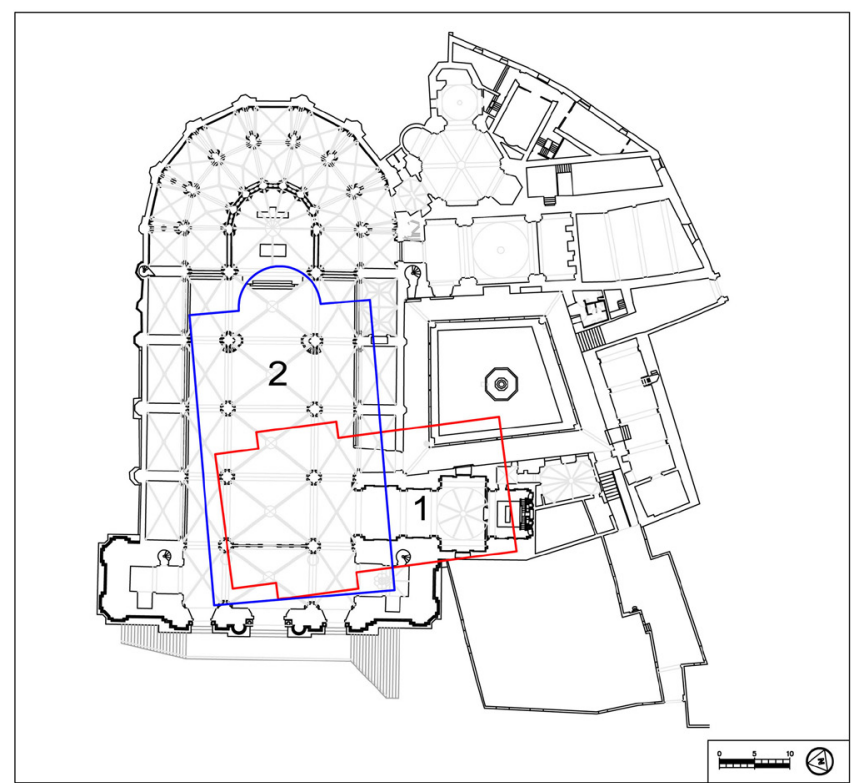

Figura 3. Hipótesis catedral románica sobre la gótica: 1. Matamoros (1932), 2. Almuni (2004)

(25), como en la de Tarragona (2012) (26) y nuevamente Burgos (2013) (27). El uso de técnicas geofísicas para localizar estas estructuras anteriores a las góticas, tiene la limitación de la comprobación física de los elementos, a diferencia de las técnicas con catas arqueológicas, como las utilizadas para determinar la seo románica de Barcelona (28). En este caso, los resultados se han completado con una hipótesis de reconstrucción gráfica (29).

\section{Así, metodológicamente se opera:}

1. Bases previas. Topografía con base informática de la catedral actual (Lluis 2000).

2. Prospección geofísica (2012-2013), (Sala 2013).

a) Determinación de estructuras visibles, vasos y fosas funerarias.

b) Creación de una cuadrícula de prospección pare el estudio geofísico.

c) Obtención de los datos.

d) Filtrado de los datos obtenidos.

3. Análisis e interpretación de resultados

a) Acción combinada de los datos físicos (Sala 2013) y la topografía (Lluis 2000).

b) Acción complementaria de los datos documentales (Almuni 1991, 2004, 2007) y (Antoon van den Wyngaerde 1563).

4. Estudio de los modelos historiográficos de la Seo de Urgel y Sant Vicenç de Cardona, y las hipótesis de las catedrales románicas de Gerona y Barcelona.

5. Superposición metrológica de los modelos volcados sobre el soporte (Lluis 2000).

6. Hipótesis de modelización de la catedral románica.
El soporte topográfico de Lluis (2000), se realiza entre 19952000, con método directo de base manual, y compensado con una estación total, SOKKIA, SET 3 BII de 10 cc de precisión angular en modo 2 cc de resolución, dotada de compensador automático de doble eje y alcance máximo con un reflector de $2.500 \mathrm{~m}$, con precisión de $+/-(3 \mathrm{~mm}+3 \mathrm{ppm})$. El sistema permite operar con un error relativo máximo de de $40 \mathrm{~mm}$, del valor acumulado de $20 \mathrm{~mm}$ del método instrumental y de $20 \mathrm{~mm}$ del directo. Fue el primer levantamiento en soporte informático hasta la fecha ${ }^{2}$.

La campaña de la prospección geofísica se realizó entre (2012-2013), mediante un Georadar IDS Hi-Mod 200-600 $\mathrm{MHz}$, con una resolución de lectura de $0,018 \times 0,2 \mathrm{~m}$. El sistema ha permitiendo obtener visualizaciones alternativas de las zonas exploradas, con un mayor detalle (60o MHz, 60 nseg) y una mayor profundidad (200 MHz, 90 nseg). La profundidad efectiva obtenida con los datos, oscila entre $1,8 \mathrm{~m}$ (600 MHz) y 2,3 m (200 MHz), calculando una velocidad de $0,095 \mathrm{~m} / \mathrm{nseg}(30)$.

Los datos permiten una acción combinada de volcado de los resultados de prospección geofísica (2012-2013) sobre la base topografía de Lluís (2000). Los resultados de esta información, permiten ser cotejados con las fuentes documentales directas, los Libros de Fábrica (Ll.o.) del Archivo Capitular (ATCo) transcritos por Almuni (2007). También con las vistas de Antoon van den Wyngaerde (1563), de la imagen del Oeste $\{$ fol.8r $\}$, y las del Norte \{fol. 7 r y 8v. (Figura 4).

\section{LOS RESULTADOS GEOFÍSICOS. LAS ANOMALÍAS}

Los resultados obtenidos mediante la prospección geofísica, a parte de lo vasos funerarios (V), han evidenciado la existencia de diferentes tipologías de anomalías. Las principales se concentran en el presbiterio (Tabla 1) -1, 2, 3- compatibles con la cabecera de la catedral románica. Otras en el inicio de la nave central; pavimentos -ha2, ha3-y -4,4b, 12,13- compatibles con la nave de la catedral románica. Otras como el relleno -ha1-, y otros elementos constructivos -5, 6, 7, 11-,

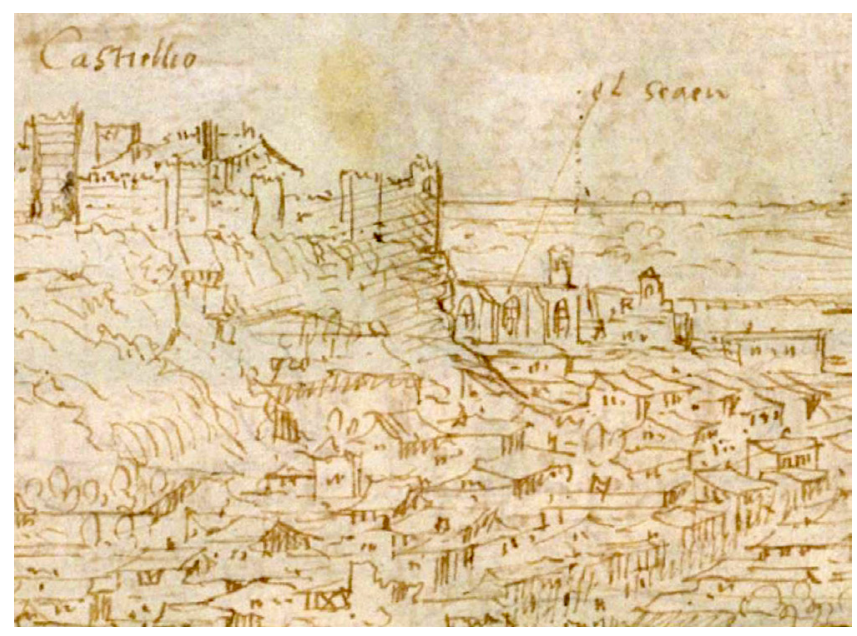

Figura 4. Detalle fachada Norte catedral de Tortosa (1563).

Antoon van den Wyngaerde. (1525-1571). Osterreichische Nationalbibliothek, Viena, Picture Archive, Cod.min 41 fol. 8 v\}.

\footnotetext{
${ }^{2}$ Plan Director Sancta Maria Dertosae. Lluis; Llorca 2000, pp. 186-192.
} 
son compatibles también con la fachada de la catedral antigua. La Capilla de la Santa Cinta no presenta prácticamente distorsiones a excepción de los vasos funerarios y el elemento -10- (Figura 5).

Anomalía -1-. En el presbítero se interpretan tres anomalías de carácter constructivo. La -1- situada en el centro, bajo la actual clave, y -2, 3- concéntrica a los pilares del actual presbiterio. Este elemento de forma circular -1-, con una magnitud semejante a los pilares del presbiterio y situado en el centro del altar, lo podemos relacionar con el pilar major. En los libros de fábrica aparece la noticia de un pilar major, a partir del mes de mayo de 1428, en plena construcción del sector central del presbiterio. Así, se plantea la hipótesis de una
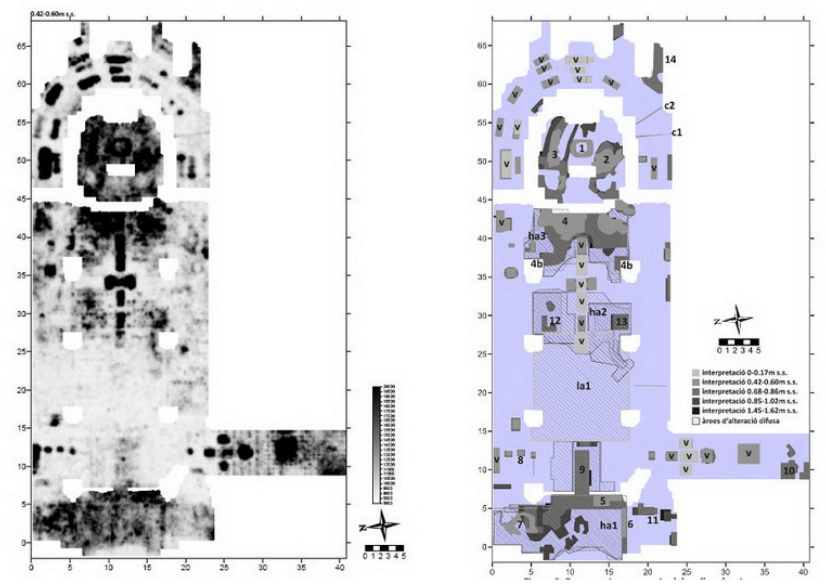

Figura 5. Anomalías estudios geofísicos, Catedral de Tortosa. Sala (2013). construcción auxiliar que luego será desmontada (31). Tras el cierre de las capillas que rodeaban a la catedral románica, en mayo de 1428, se empieza construir el pilar major. Se trata de una acción coincidente con las obras de derribo en la cabecera de la catedral románica, realizadas a partir del mes de agosto. El pilar se situó, según se observa a partir del Georadar (201213), tal y como citan; "començam de desfer lo bastiment de la cerqua e començam lo bastiment del pilar major darrera l'altar, e forenhi III mestres de axa e hun fadri...» \{ACTo, 11. o. 1427-1428, núm. 13, fol. 15r.\}. El pilar se construye antes de la cubrición de las primeras bóvedas del deambulatorio, realizadas en julio de 1431, y desmontado en marzo de 1440, tras el descimbrado del presbiterio. El carácter eventual, lo demuestra su posterior desmontaje, en marzo de 1440 \{ACTo, 1l. o. 1439-1441, fol. 62r.\}, a la vez que su escasa cimentación, como indica el corte D del Georadar (2102-13).

Anomalía -2, 3-. Elementos constructivos concéntricos al muro de cerramiento del presbiterio gótico. La $-3-$, de forma arqueada, irá ganando complejidad y dimensión con la profundidad hasta trazar una forma de arco. Pueden ser interpretados como los muros del ábside central de la catedral románica. El hecho de que exista un tramo recto y otro curvo, puede responder a la estructura clásica de una estructura de bóveda de cañón, rematada con una de cuarto de esfera, habitual en los ábsides lombardos.

Anomalías -4b, 12 y 13-. La interpretación geofísica determina estos elementos como elementos constructivos. Todos ellos tienen la característica de estar próximos a los pilares de la sección gótica. Están situados hacia el interior de la nave central, y más próximos al presbiterio que los pilares actuales, interpretamos estos elementos como los pilares de la

Tabla 1. Listado de anomalías identificadas en la prospección geofísica.

\begin{tabular}{|c|c|c|c|c|}
\hline \multicolumn{5}{|c|}{ CUADRO DE ANOMALIAS PROSPECCIÓN GEOFÍSICA. CATEDRAL TORTOSA (2012-2013) } \\
\hline Referencia & Coronamiento (m) & Profundidad (m) & Ubicación & Interpretación \\
\hline la1 & o & 0,17 & Nave central & Pavimento \\
\hline $\mathrm{c} 1$ & 0,42 & 0,6 & Girola & Conducciones \\
\hline c2 & 0,42 & 0,6 & Girola & Conducciones \\
\hline ha1 & 0,42 & 0,42 & Nave central & Elementos de escombros \\
\hline ha2 & 0,5 & 0,5 & Nave central & Pavimento \\
\hline ha3 & 0,5 & 0,5 & Nave central & Pavimento \\
\hline 1 & 0,3 & 0,3 & Presbiterio & Elemento constructivo colmatado \\
\hline 2 & 0,42 & 0,42 & Presbiterio & Elemento constructivo o cavidad colmatada \\
\hline 3 & 0,42 & 0,42 & Presbiterio & Elemento constructivo \\
\hline 4 & 0,42 & 0,42 & Nave central & Elemento constructivo \\
\hline $4 \mathrm{~b}$ & 0,68 & 0,68 & Nave central & Elemento constructivo \\
\hline 5 & 0,5 & 0,5 & Nave central & Muro \\
\hline 6 & 0,42 & 0,42 & Nave central & Muro \\
\hline 7 & 0,5 & 0,5 & Nave central & Elemento constructivo \\
\hline 8 & 0,42 & 0,42 & Nave central & Elementos metálicos \\
\hline 9 & 0,5 & 0,5 & Nave central & Elemento constructivo \\
\hline 10 & 0,68 & 0,68 & Capilla S. Cinta & Elemento constructivo \\
\hline 11 & 0,5 & 0,5 & Nave central & Elemento constructivo \\
\hline 12 & 0,68 & 0,68 & Nave central & Elemento constructivo \\
\hline 13 & 0,68 & 0,68 & Nave central & Elemento constructivo \\
\hline 14 & 0,68 & 0,68 & Girola & Elemento constructivo \\
\hline 15 & 0,2 & 0,2 & Nave central & Elemento constructivo \\
\hline 16 & 2,5 & 2,5 & Nave central & Elemento constructivo \\
\hline
\end{tabular}


catedral románica. El nivel de los cimientos de los primeros pilares de la nave gótica es objeto de peritaje. Así, en 27 septiembre 1440, en el pilar de la epístola, se determina que han de tener hasta el arranque de la base del pilar, una medida de, XXVII palms de cana $(627 \mathrm{~cm})$, situándolo a sis palms mes avant de la obra vella $(139 \mathrm{~cm})^{3}$. El 13 de agosto de 1442, se realiza la excavación del pilar del evangelio, que dice entrar 20 palmos de profundidad y que en aquel momento entrava VIIII palms mes que lo pilar veyll ${ }^{4}$. Por la documentación determinamos que los cimiento de los pilares de la catedral románica eran perfectamente visibles y situados en la zonas próximas al pilar, ya que los cimientos tenían una dimensión en dirección a la nave, y sobre el eje del pilar, de $371 \mathrm{~cm}, \mathrm{y}$ perpendicularmente, hacia la nave lateral de $465 \mathrm{~cm}$.

Anomalía -5-. Los métodos geofísicos la determinan como un importante muro. Esta anomalía abarca gran parte del cuerpo de la nave central. Se puede interpretar como el límite de la catedral de románica, cuya existencia prevalece hasta 1703, en cuyo mes de enero se empieza a desmontar ${ }^{5}$. La imagen pertenecería a la vista desde el Oeste de la catedral de Antoon van den Wyngaerde (1563) \{O.N. Cod.min 41, fol. 8 r\}.

\section{LOS MODELOS HISTORIOGRÁFICOS}

La cronología de la catedral románica consagrada en 1178, se enmarcaría dentro de un sistema constructivo definido como lombardo por Josep Puig i Cadafalch (1867-1956). La ejemplificación la realiza sobre el modelo de la catedral de la Seu d’Urgell (c. 1116-1122). El sistema constructivo inicial, consta de bóveda de cañón y arcos de resalto o fajones en la nave central, y de bóvedas de arista en las naves colaterales. Las pilastras de cruz latina soportaran en sus brazos los arcos torales y formeros. Sobre la planta de la cruz se alojan cuatro cuartos de círculo que generarán la estructura de las bóvedas de arista en las colaterales y las arquivoltas de refuerzo de los fajones. La sección transversal inicial consta de una nave central doblando las naves colaterales, y posteriormente será modificada con la colocación de una bóveda de cuarto de círculo (32).

Otro modelo constructivo y tipológico similar pudiera ser un modelo anterior como el de Sant Vicenç de Cardona (1040). La construcción esta considerada como un modelo más primitivo con referencias no solo en Lombardía y Sur de Francia, sino también de Constantinopla (Fernie 2000, 243-256). Se trata de un modelo constructivo con bóveda central de cañón, las naves laterales con tres bóvedas de arista sobre arcos fajones y con pilares en forma de cruz latina que recogen los resaltes de la arquería de las bóvedas (33) (34).

La imagen que determina Antoon van den Wyngaerde en la vista de la ciudad de Tortosa (1563) permite una visión lateral, desde el Norte donde coexisten la construcción románica y la gótica

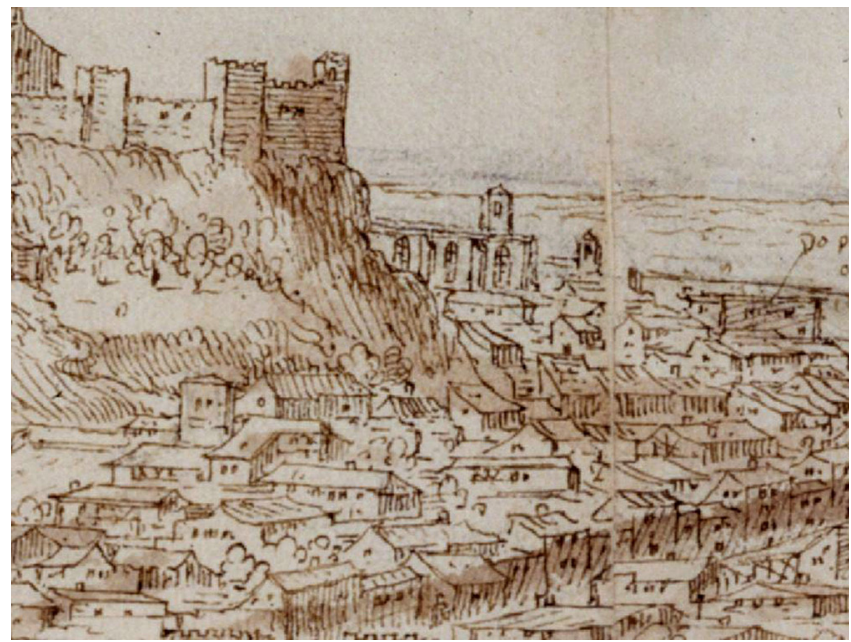

Figura 6. Detalle fachada Norte catedral de Tortosa (1563). Antoon van den Wyngaerde. (1525-1571). Osterreichische Nationalbibliothek, Viena, Picture Archive, Cod.min 41 ffol. 7 r\}.

\{Cod.min 41; fol. 7r, y fol $8 \mathrm{v}$ \} (Figura 6). La imagen es similar a la de la catedral de Gerona, de la Taula de la Pietat (ca.15431550) de Pere Mates (c.1490-1558) en el Museu d'Art de Girona, procedente del monasterio de Sant Esteve de Banyoles (35).

Es importante resaltar el engranaje necesario de los trabajos de demolición de la antigua catedral románica y de construcción de la gótica. El proceso de la catedral de Tortosa ha de ser similar a lo establecido en las catedrales de Gerona y Barcelona, con la superposición de los modelos románicos sobre las actuales catedrales. Así es posible el ensayo las de las construcciones románicas de los modelos de la catedral de la Seo de Urgel (Figura 7.1) y Sant Vicenç de Cardona (Figura 7.2), aún existentes, y las hipótesis de las catedrales románicas de Barcelona (Figura 7.3) y Gerona (Figura 7.4), superpuestas a las góticas.

\section{LA BASE METROLÓGICA}

A partir de las anomalías identificadas en los estudios geofísicos, es posible deducir tres consideraciones básicas sobre la composición de la construcción románica y su medida:

a) disposición de una cabecera en forma de ábside, concéntrica al presbiterio gótico con un ancho aproximado de $5 \mathrm{~m}$ en la boca del ábside, según la Anomalía -2, 3-.

b) existencia de una construcción anterior inscrita en la nave central, apoyada sobre pilares con ángulos rectilíneos en la base. La distancia entre estos elementos, según las imágenes, es del orden de 7,00 m. Anomalías -4b, $4 \mathrm{~b}-\mathrm{y}-\mathrm{l} 2,13-$.

\footnotetext{
3 (Almuni 2007 2: 818-819) «consellaven que sens perill de la obra podien carregar com fos fet lo dit pilar hagues de altava fins en la cara de la (terça) XXVII palms de cana, sis palms mes avant de la obra vella, en la fi del qual clot fonch hobrat caba, tepar e argila, de amplaria XVI palms e de largaria XX palms».

4 (Almuni 2007 2: 829) «que lo clot del pilar \{que havia fet per continuar la dita obra\} entrava XX palms de cana de Tortosa, e encara que havia intrar VI palms mes. Item que \{lo dit clot\} entrava VIIII palms mes que lo pilar veyll».

${ }_{5}^{5}\left(\mathrm{O}^{\prime}\right.$ Callaghan 1888, 184). Acta de 19 de enero de 1703. «Attés que lo dilluns se ha de comensar a derrocar la obra vella, per a la prosecusió del estall, lo diumenge en la tarde después de completes de cante una salve a Nostra Senyora, colocada la reliquia de la Santa Cinta en lo altar major. Y lo dilluns se diga una misa matinal en la capella de Nostra Senyora, per a que Nostre Senyor sia servit per sa intercesió, guardar-nos del dit enderroch, y sempre, de tota desgracia. Se participe per lo Secretari als Señors Procuradors, per si voldrán asistir a dita Salve».
} 

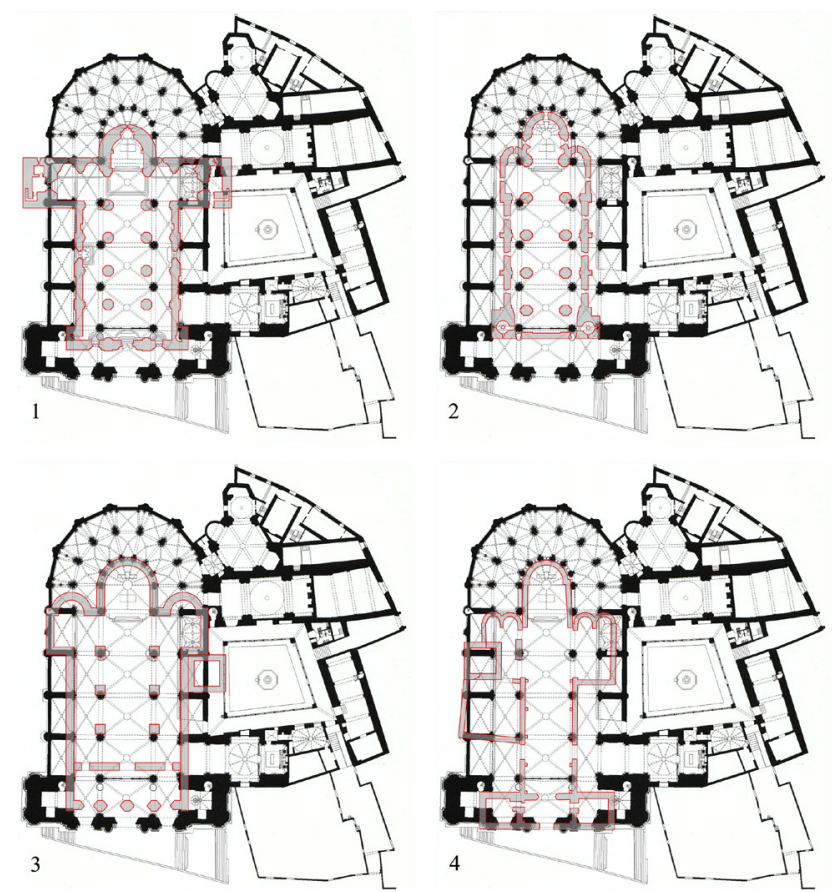

Figura 7. Superposición sobre la catedral gótica de Tortosa de las catedrales románicas de la Seo de Urgel (1), Sant Vicenç

de Cardona (2) y las hipótesis de las catedrales románicas de Barcelona (3) y Gerona (4).

c) un gran muro dispuesto tras el inicio del último tramo de nave sobre la actual capilla de la Santa Cinta, con orientación Norte a Sur. La medida interior entre las anomalías $-2,5-\mathrm{y}-5$ - es de unos 42,00 m.

Por otra parte, carecemos de información geofísica sobre el ancho de las naves colaterales de la construcción románica, así como de la morfología de las absidiolas. Con ello y en base a los datos obtenidos, se formulará una hipótesis según las referencias metrologías con que se construyó la catedral de Tortosa.

En el inicio de la obra gótica, el maestro impone la unidad de medida, solicitando para el inicio de la nueva catedral (1347), la construcción de una cana; Item fiu fer lo maestre de/la obra a-n Antoni ferrer una cana de ferre per pendre mesures de l'obra costa... V.s \{Ll.o.2 1345-1347, f.36 v\} (36). El patrón básico de las medidas, de los Llibres d’Obra (ACTo), es la cana. La cana tiene 8 palmos y el palmo 12 dedos. La cana de Tortosa esta definida en el Libro IX, Rubrica 15.5 de las Consuetudines Dertosae (1272) \{AHCTE cod.53, fol.256r\}, y en la copia de 1346, Llibre de les Costums Generals feutes de la insigne ciutat de Tortosa \{FBMPM, fol.10or\}, que es cuando se inicia la catedral gótica. Comparando los documentos de la unificación de la cana de Tortosa a la de Barcelona de (24-VII-1593), se determina que la Cana de Tortosa ${ }^{6}$, utilizada en la catedral, tiene $1.858 \mathrm{~cm}$ y el palmo $23,23 \mathrm{~cm}$.

\section{SIMULACIÓN DEL MODELO}

La definición tipológica de la catedral románica de Tortosa toma como referencia principal el modelo constructivo de Sant Vicenç de Cardona. Se determinan las dimensiones teóricas de la seo románica mediante métodos de proporcionalidad geométricos, de acuerdo con las anomalías identificadas y las referencias tipológicas. En el modelo resultante se establece una longitud total de 28 canas (224 palmos, $52,04 \mathrm{~m}$ ) y un ancho de 10 canas y 4 palmos (84 palmos, 19,51 m) (Figura 8).

Así, el edificio se estructura con una nave central y dos colaterales de menor altura, un transepto con dos absidiolas y el ábside principal, coincidente con la actual ubicación del presbiterio gótico. 4 crujías dividen el espacio cubierto por una bóveda de cañón en la nave central, apoyada sobre arcos de medio punto sobre pilares en forma de cruz. El transepto estaría cubierto por una cúpula esférica sobre la que se construiría el cimborrio. El ábside y las absidiolas estarían cubiertos por semicúpulas esféricas. Cabe suponer que en la crujía de acceso estaría ubicado el atrio del coro (Figura 9).

Las anomalías -2, 3- y -5- determinan la longitud interior de la catedral románica, a la que hemos asignado 21 canas. El ancho de la nave central se establece a partir de las anomalías $-4 \mathrm{~b}, 4 \mathrm{~b}-\mathrm{y}-\mathrm{l} 2,13-$, separadas por una distancia definida en 30 palmos $(696,9 \mathrm{~cm})$. Así la nave central dispondría de una bóveda de cañón de 30 palmos, mientras que las colaterales tendrían un ancho de 16 palmos ( 2 canas, 371,68 cm), más el ancho de los elementos de soporte (6 palmos, $139,38 \mathrm{~cm}$ ). La medida será coincidente con los bordes internos de los vasos funerarios de las naves colaterales.

El modulo estructural de las anomalías -4b, 4b- y -l2, 13-, es de 36 palmos: 30 corresponderían al cañón y 6 al arco de resalto. Estas proporciones serán similares a los modelos de la Seo de Urgel y Cardona, y por ello establecemos un pilar cruciforme de 10 palmos, con unos muros de cerramiento de 6 palmos.

El ábside principal según -2,3- tendrá una longitud de 44 palmos, y un crucero de 36 siguiendo la modulación de la estructura. Con ello, disponemos de una nave principal de 144 palmos, un crucero de 36 palmos y un ábside de 44 palmos $(44+36+44=224$ palmos, 28 canas $)$. De las absidiolas no disponemos de datos específicos así que se les ha asignado un
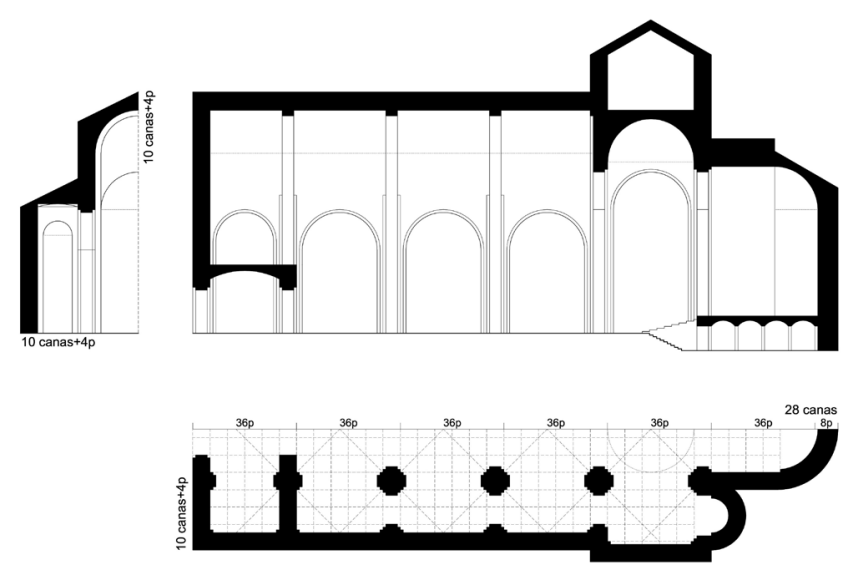

Figura 8. Base metrológica de la hipótesis seo románica. J. Lluís, A Costa, A. Ferré (2013).

\footnotetext{
${ }^{6}$ El rey Felipe II (1527-1598) en las Cortes de Monzón (1585). Capitulo 89, unifica criterios métricos. Los procuradores de la Ciudad de Tortosa remiten la reducción de la cana de Tortosa a Barcelona. AHCTE, 387 (Comú II-63) Registre.
} 


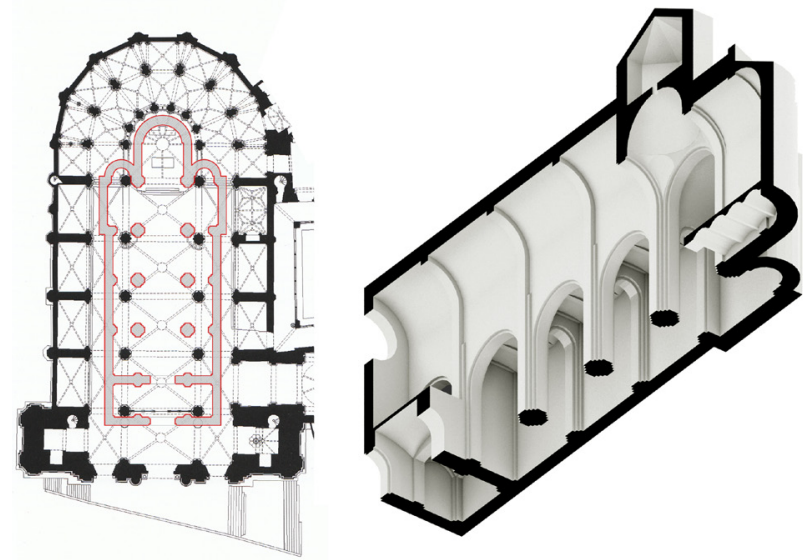

Figura 9. Hipótesis seo románica, implantación y axonometría. J. Lluís, A Costa, A. Ferré (2013).

modelo similar a las hipótesis de Barcelona y Cardona, determinando un transepto con 92 palmos.

La hipótesis de la sección se establece, al igual que la planta, según los modelos de la iglesia de Cardona. La clave de los arcos de medio punto, situados entre la nave central y las colaterales, se sitúa a 42 palmos $(9,75 \mathrm{~m})$ de altura. El cénit de la bóveda de cañón central se sitúa a 84 palmos de altura (10 canas y 4 palmos, $19,51 \mathrm{~m}$ ) mientras el remate de las colaterales, con bóvedas muy rebajadas, estaría a una altura aproximada de unos 45 palmos (10,45 m).

\section{CONCLUSIÓN}

Los resultados del estudio geofísico aportan los primeros datos de carácter físico de la antigua construcción románica de Tortosa. Con esta investigación, se descarta la tesis de Matamoros (1932) (Figura 4.1), establecida en base a la recopilación de la historiografía clásica del siglo XIX, y se precisa la ubicación de la hipótesis establecida por Almuni (2004) (Figura 4.2), anunciada por Querol (1992), sobre la orientación Este-Oeste.

Una vez determinada la ubicación de la antigua seo, es posible deducir el proceso constructivo, deconstructivo. Se establece un dialogo entre lo nuevo, gótico, y lo viejo, románico. La nueva edificación es concéntrica a la anterior (Figura 10) donde las anomalías situadas en el presbiterio -2, 3-, están inscritas en los pilares del deambulatorio. Por otra parte, los pilares en los dos primeros tramos de la nave central actual, producen un movimiento a la vez de circunscripción y traslación respecto a las anomalías -4b, 12 y 13-, identificadas como pilares de la seo románica. Este proceso operativo permite, desde el punto de vista litúrgico, no alterar los oficios que se celebran en la Seo. El proceso de derribo del edificio anterior no se realiza hasta que la nueva construcción puede entrar en uso, prolongándose temporalmente la utilidad de la construcción románica. El desmontaje no se produce
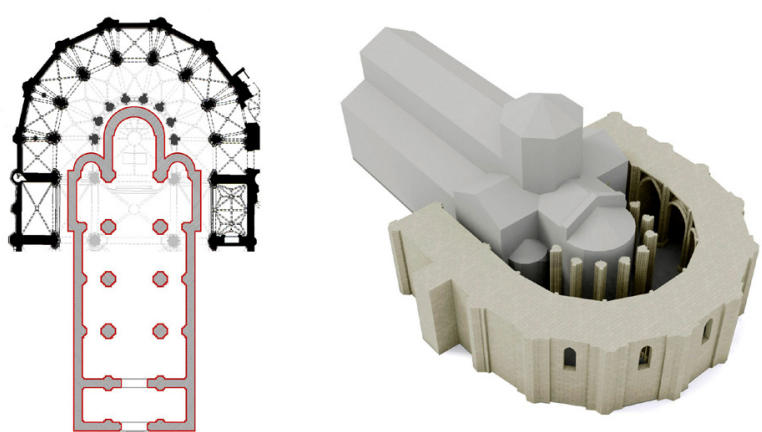

Figura 10. Superposición espacial de la seo románica sobre el ábside gótico. J. Lluís, A Costa, A. Ferré (2013).
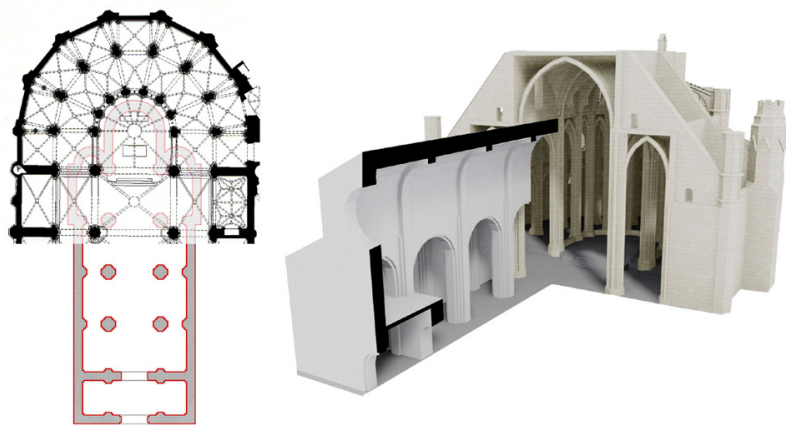

Figura 11. Superposición espacial de modelos de la hipótesis seo románica sobre la actual en el proceso de construcción / deconstrucción. J. Lluís, A Costa, A. Ferré (2013).

hasta que no es estrictamente necesario, debido a su utilidad como elemento auxiliar de construcción de la nueva catedral (Figura 11).

La colocación estratégica de los elementos constructivos nuevos, especialmente muros y pilastras, son compatibles con los que se están desmontando. En general el desmontaje de una bóveda de cañón se realiza actuando mediante una sección de corte que será perpendicular a su directriz. No ocurrirá de la misma manera con el derribo de una bóveda de arista.

En la operación de desmontaje se ha de observar el equilibrio de los empujes perpendiculares al eje de la nave. Estos empujes horizontales han de estar equilibrados a la vez, ya que los centrales del cañón y los colaterales disponen de un punto de aplicación a diferente altura. Una posibilidad pudiera ser la disposición de elementos auxiliares para equilibrar estos efectos de contrarresto, ejecutados como elementos diferenciados, o bien como parte de la nueva construcción. El sistema operativo del contrarresto en la construcción de las nuevas bóvedas, respecto a la antigua construcción, antes del cerramiento de las bóvedas del presbiterio, es un tema capital para entender el equilibrio de la nueva construcción. Este proceso ha quedado fuera del alcance de esta parte de la investigación.

\section{REFERENCIAS}

(1) O’Callaghan, R. (1888). Anales de Tortosa III, pp. 295-307. Tortosa: Imprenta Católica de Gabriel Llasat.

(2) Sebastián, S. (1994). Mensaje Simbólico del Arte Medieval. Arquitectura, Liturgia e Iconografía, pp. 352-355. Madrid: Ediciones Encuentro.

(3) Van der Ploeg, K. (2003). On the correct usage and characterization of Christian imagery within the liturgical milieu: Durandus of Mende's «Rationale Divinorum Officiorum» and the function of imagery in art. Speculum a Journal of Medieval Studies, 78(I.4): 1287-1288. 
(4) Mambelli, F. (2004). Il problema dell'immagine nei commentari allegorici sulla liturgia: Dalla Gemma Animae di Onorio d'Autun (1120 ca.) al Rationale divinorum officiorum di Durando di Mende (1286-1292). Studi Medievali, 45(1): 121-158.

(5) Street, G.E. (1865). Some account of gothic architecture in Spain, p. 318. London: John Murray.

(6) Bassegoda i Nonell, J. (1973). La catedral de Barcelona: su restauración 1968-1972, p. 55. Barcelona: Editores Tecnicos Asociados S.A.

(7) Matamoros, J. (1932). La catedral de Tortosa. Trabajos monográficos acerca de su construcción y de su contenido artístico y religioso, p. 8-16. Tortosa: Editorial Católica.

(8) Haverkamp-Begemann. E. (1969). The Spanish Views of Anton van den Wyngaerde. Master Drawings, vol. 7.

(9) Kagan, R.L. (1986). Ciudades del Siglo de Oro. Las Vistas Españolas de Anton Van den Wyngaerde. Madrid: El Viso.

(10) Galera, M. (1998). Antoon van den Wijngaerde, pintor de ciutats i de fets d'armes a l'Europa del Cinc-cents. Cartobibliografia raonada dels dibuixos i gravats, i assaig de reconstrucció documental de l'obra pictòrica. Madrid-Barcelona: Fundación Carlos de Amberes-Institut Cartogràfic de Catalunya.

(11) Querol, A. (1992). La Cuaresma del año Olimpico. Tortosa: Programa Oficial de Setmana Santa.

(12) Almuni, V. (1997). Santa Maria de Tortosa. En Catalunya Romànica XXVI, (pp.117-120). Barcelona: Enciclópedia Catalana.

(13) Lluis, J., Llorca, A. (2000). Pla Director Sancta Maria Dertosae. Catedral de Tortosa, pp. 74-75 Tortosa: Generalitat de Catalunya.

(14) Almuni, V., Lluis, J. (2000). Sancta Maria Dertosae. Catedral de Tortosa. Guia Histórica i Descriptiva, pp. $30-32$. Tortosa: Bisbat de Tortosa.

(15) Almuni, V. (2004). La catedral románica de Tortosa. Aproximació documental a la seva historia. Recerca, 8: $211-250$.

(16) Almuni, V. (2007). La catedral de Tortosa als segles del gòtic. Vol. 1, p. 253-282. Barcelona: Fundació Noguera. Col-lecció Estudis.

(17) Atkinson, R. J. C. (1963). Resistivity surveying in archaeology. En Pyddoke E. (Ed.), The scientist and Archaeology, (pp. 1-30). London: Phoenix House.

(18) Aspinall, A., Haigh, B. (1997). Twenty five years of archaeological prospection. En Archaeology in the age of the internet: CAA 97 - Computer applications and quantitative methods in archaeology: proceedings of the 25th anniversary conference, vol.1: (pp.13-18). Birmingham: University of Birmingham.

(19) Dabas, M. (1998). La prospection géophysique. En Ferdière, A. (Ed.), La prospection. Collection Archéologiques, (pp. 161-207). París: Errance.

(20) Dabas, M. (2000). Géophysique et archéologie. Comment construisait-on au moyen âge? Dossiers d'archéologie. Architectures Médiévales, 25: 36-41.

(21) Dabas, M., Camerlynck, C., Freixas i Camps, P. (2000). Case History: Simultaneous use of electrostatic quadrupole and GPR in urban context: Investigation of the basement of the Cathedral of Girona (Catalunya, Spain). Geophysics, 65(2): 526-532, doi: http://dx.doi.org/10.1190/1.1444747.

(22) Freixas, P. (2000). La catedral de Girona, redescobrir la Seu Romànica. Els resultats de la recerca del Projecte Progres, pp. 61-64. Girona: Ajuntament de Girona.

(23) Pérez, V., Canas, J.A., Pujades, Ll., Clapés, J., Caselles, O., Garcia, F., Osorio, R. (200o). GPR survey to confirm the location of ancient structures under the Valencian Cathedral (Spain). Journal of Applied Geophysics, 43(2-4): 167-174, doi: http://dx.doi.org/10.1016/So926-9851(99)00056-7.

(24) García, L. M. (2002). La antigua catedral románica de Burgos. Revista de Obras Públicas, 149(3424): 51-57.

(25) Brito-Schimmel, P., Carreras, C. (2010). Metodología para la prospección geofísica en arqueología: Apuntes a partir de los trabajos de Iesso, Can Tacó, Molins Nous y el Goleró. Lucentum, (29): 9-22.

(26) Macias, J.M., Muñoz, A., Teixell, I. (2012). A la Recerca del Temple d'August, les intervencions arqueològiques a la catedral de Tarragona. Plecs d'Historia Local, 146: 3-5.

(27) Espinosa, A.B., Garcia, L.M., Aracil, E. (2012, 21 de septiembre). Application of electromagnetic techniques (Georadar) to investigate Burgos Cathedral subsoil and foundation. En Proceedings of the 4th International Conference on Site Characterization 4, ISC-4, (Vol. 2, pp.1403-1408). Pernambuco-Brazil.

(28) Beltrán, J., Lorés, I. (2005). La catedral romànica de Barcelona: revisió de les dades arqueològiques i de l'escultura. Quarhis: Quaderns d'arqueologia i història de la ciutat de Barcelona, (1): 101-117.

(29) Sobrino, M., Bustos, C. (2008, diciembre). Nueva hipótesis dibujada de la catedral románica de Barcelona. En Actas del XII Congreso Internacional de Expresión Gráfica Arquitectónica (pp. 811-818). Madrid.

(30) Sala, R. (2013). Memòria d'Intervenció Prospecció geofísica a la catedral de Tortosa. SOT Prospecció Arqueològica.

(31) Lluis, J., Almuni, V. (2011, 26-29 de octubre). La clave de la clau. El cierre constructivo del presbiterio gótico. En: Actas del Séptimo Congreso Nacional Historia de la Construcción, Santiago de Compostela (pp. 753-761). Madrid: Instituto Juan de Herrera.

(32) Puig, J., Pujol, P. (1918). Santa Maria de la Seu d'Urgell, pp. 57-71. Barcelona: Tallers d'Arts gràfiques Henrich i Ca.

(33) Reed, P. (2000). Structural Rationalism and the Case of Sant Vicenç de Cardona. Architectural History, 43: 24-41, doi: http://dx.doi.org/10.2307/1568684.

(34) Reed, P. (2000-2001). Racionalismo estructural y el caso de San Vicente de Cardona. Lambard. Estudis d'Art Medieval, 13: 163-184.

(35) Freixas, P. (2005-2006). La façana gòtica de la catedral de Girona. Locvs Amoenvs, 8: 123-132.

(36) Almuni, V. (1991). L'Obra de la Seu de Tortosa (1345-1441), p. 214. Tortosa: Cooperativa Gràfica Dertosense. 